\title{
A Conceptual Design of Transport Lines for a Heavy-Ion Inertial-Fusion Power Plant
}

\author{
by \\ David L. Judd \\ from \\ Lawrence Berkeley National Laboratory (on behalf of U.S. HIFS-VNL) \\ 1 Cyclotron Road, Berkeley, CA 94720 \\ Accelerator Fusion Research Division
}

November 1998

This work was supported by the Director, Office of Science, Office of Fusion Energy Sciences, of the U.S.

Department of Energy under Contract No. DE-AC02-05CH11231. 
This document was prepared as an account of work sponsored by the United States Government. While this document is believed to contain correct information, neither the United States Government nor any agency thereof, nor The Regents of the University of California, nor any of their employees, makes any warranty, express or implied, or assumes any legal responsibility for the accuracy, completeness, or usefulness of any information, apparatus, product, or process disclosed, or represents that its use would not infringe privately owned rights. Reference herein to any specific commercial product, process, or service by its trade name, trademark, manufacturer, or otherwise, does not necessarily constitute or imply its endorsement, recommendation, or favoring by the United States Government or any agency thereof, or The Regents of the University of California. The views and opinions of authors expressed herein do not necessarily state or reflect those of the United States Government or any agency thereof or The Regents of the University of California.

This work was supported by the Director, Office of Science, Office of Fusion Energy Sciences, of the U.S. Department of Energy under Contract No. DE-AC02-05CH11231. 


\section{A CONCEPTUAL DESIGN OF TRANSPORT LINES FOR A HEAVY-ION INERTIAL-FUSION POWER PLANT \\ David L. Judd \\ November 1998}

(Discard a preliminary version dated October 1998 which contains errors.)

\section{Introduction}

Two groups of heavy-ion beam pulses are to be transported from an induction linear accelerator to a target in an inertial fusion power plant. A group of twenty prepulses arrives first, emerging at lower energy upstream from the linac exit; the second group, of forty main pulses, have full energy. For definiteness we use numerical values for these beams developed by Wayne Meier; both beams consist of singly charged ions with mass number 200, having prepulse and main pulse energies of $3 \mathrm{GeV}$ and $4 \mathrm{Gev}$, respectively.

\section{The Approach to a Cone of Final-focus Arrays}

Each group of beams is divided into two subgroups which approach the target from opposite directions. The final approach of each beam is along the straight axis of a final focusing array of quadrupole magnets. A single array can be represented as shown:

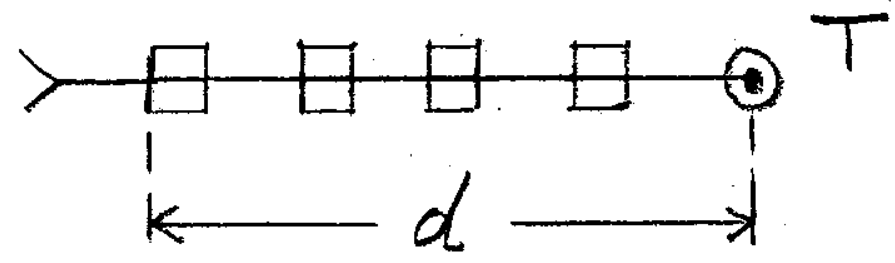

The length $\mathrm{d}$ of the array has been set by Meier at 25 meters. We take the distance from the downstream surface of the last magnet to the target to be $5 \mathrm{~m}$. The main-pulse beams approaching the target from one side will have their axes distributed on the surface of an outer cone whose half-angle $\theta$ is important because it determines the maximum transverse dimension of the bundle of beams. The axes of the prepulse beams will lie on the surface of a cone coaxial with the first one, whose half-angle is smaller because there are fewer prepulse beams.

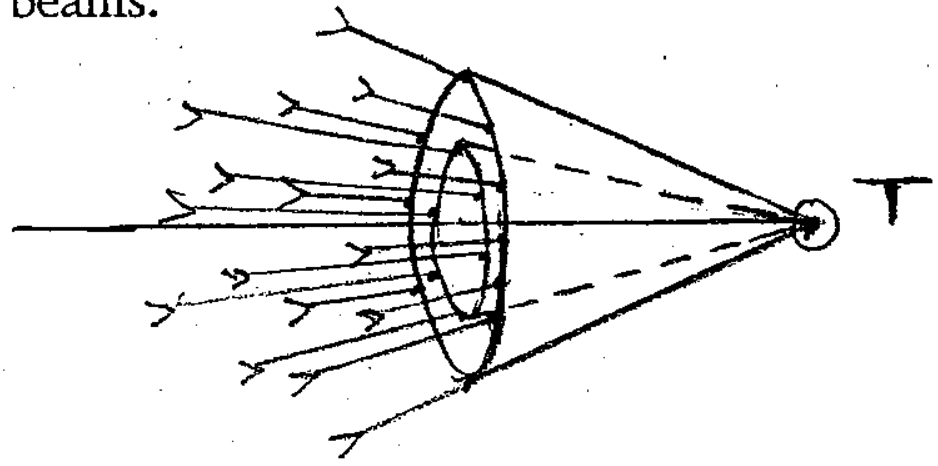


All the beams of each group must have axes on the same cone, because if not they will have different path lengths to the target from the place where they diverge from the tight bundle in which they have been transported from the linac. The design is sensitive to the transverse dimension of the final quadrupole focusing magnets. We assume that these magnets are square in cross section with side $s$. The numerical value of $s$ is important because it fixes the angle $\theta$ of the main-pulse cone, and therefore the maximum radius of the array of beams in the region upstream from the target, as well as the length of this region. For evaluating these dependences it is useful to develop expressions for the annular packing of $\mathrm{N}$ identical squares of side s; they are given here, with symbols defined on the sketch.

$$
\begin{gathered}
\psi=\pi / \mathrm{N} ; \cot \varphi=2+\cot \psi ; \mathrm{a}=(\mathrm{s} / 2) / \sin \psi ; \mathrm{b}=(\mathrm{s} / 2) / \sin \phi ; \\
\mathrm{c}=\mathrm{a} \cos \psi=(\mathrm{s} / 2) \cot \psi ; \\
\mathrm{d}=\mathrm{b} \cos \phi=(\mathrm{s} / 2) \cot \phi .
\end{gathered}
$$

The radial distance from the central point to the center of a square is

$$
r=(s / 2)(\cot \psi+1)=(s / 2)(\cot \phi-1)
$$

If twenty beams are to have this configuration, $\psi=90, \phi=6.8590$, and $\mathrm{r}=3.657 \mathrm{~s}$.

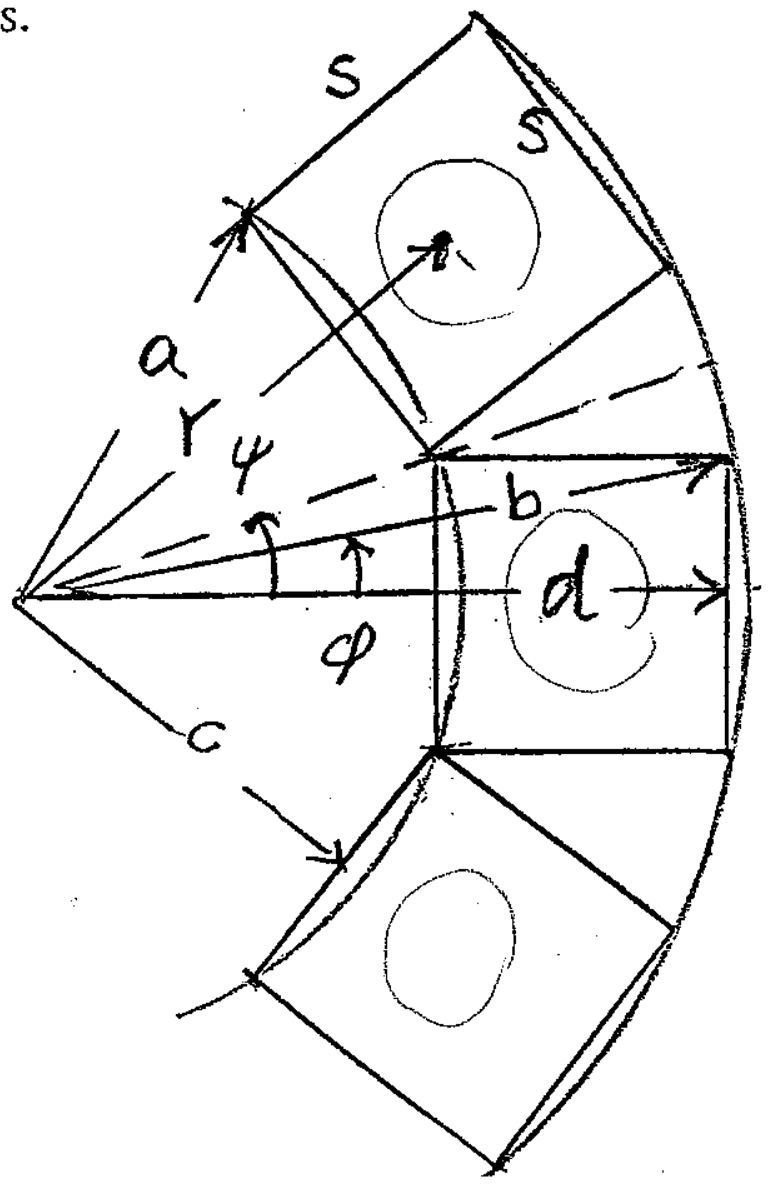


The surfaces of these squares must be tilted to face the target; we will assume that this rotation of each face is about an axis through its center in its plane and normal to $r$. The half-angle $\theta$ of the cone containing all the centers is then the sine of $\mathrm{r} /(5 \mathrm{~m})$.

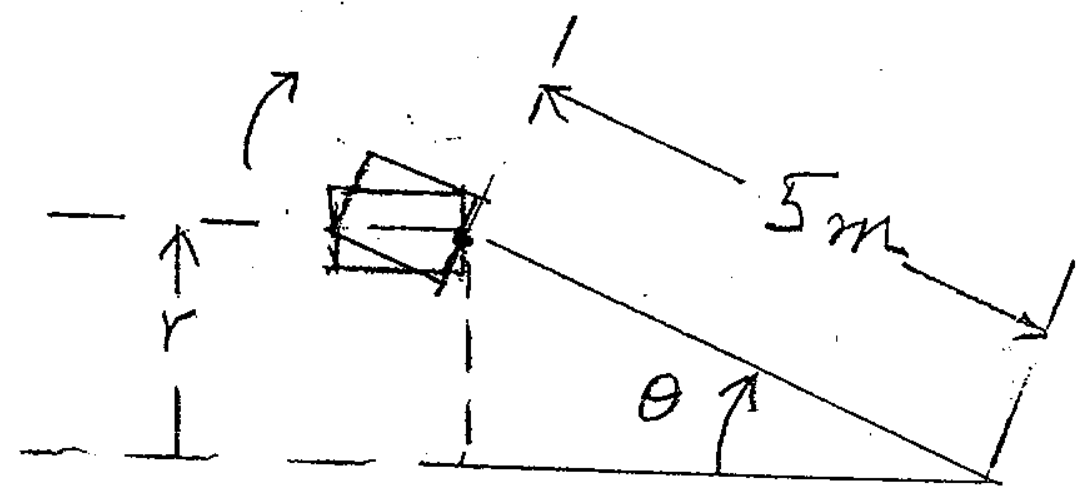

The subgroup of main-pulse beams must be separated so that each can approach the target along its own line. We assume that each of them starts from the snug transport bundle in the plane of its final approach, at the same small radius e from the main axis. [These conditions are not necessarily exact because they depend on the arrangement of the twenty main-pulse beams and the ten prepulse beams in their bundles as they approach the target region, but corrections for their errors may be regarded as fine tuning to be worked out later.] We assume, with Meier, that the curved paths are circular arcs with radius $\rho$ determined by bending field elements of field $B_{O}$ having occupancy fraction $\eta$, giving a mean bending field $B$ $=\mathrm{B}_{\mathrm{O}} \eta ; \rho=\mathrm{p} / \mathrm{Bq}$ with $\mathrm{p}$ and $\mathrm{q}$ the ion momentum and charge. Meier has taken the values $B_{O}=4$ Tesla and $\eta=0.4$, so that $B=1.6 \mathrm{~T}$. For the main-pulse beams $\rho=80.9 \mathrm{~m}$ and for prepulse beams $\rho=70.1 \mathrm{~m}$.

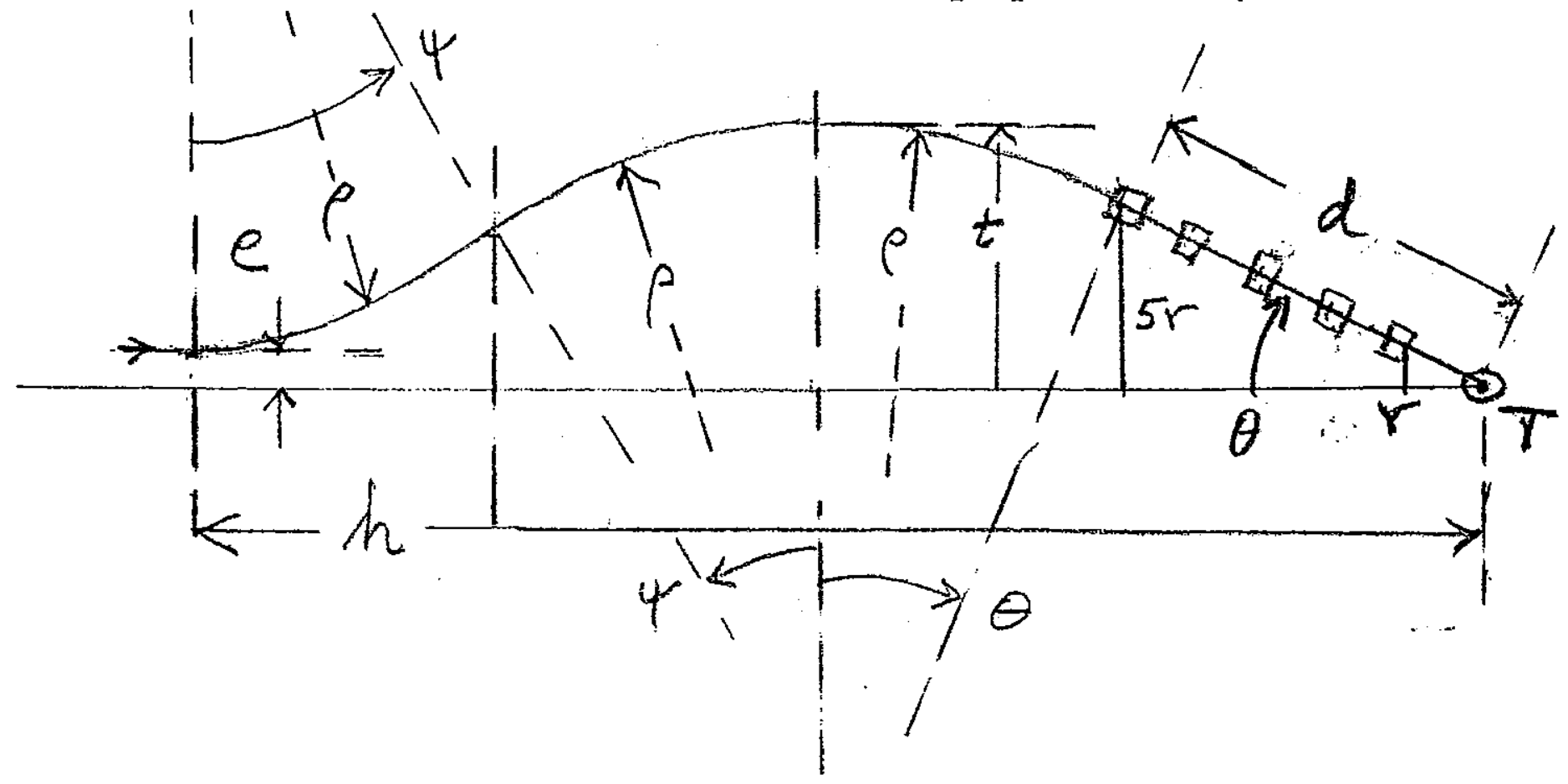


Using the symbols defined on the figure, the geometrical relations are:

$$
\begin{gathered}
\sin \theta=5 \mathrm{r} / \mathrm{d} ; \mathrm{t}=\mathrm{d} \sin \theta+\rho(1-\cos \theta) ; \\
\psi=\cos ^{-1}[1-(\mathrm{t}-\mathrm{e}) / 2 \rho] ; \quad \mathrm{h}=\rho(2 \sin \psi+\sin \theta)+5 \mathrm{r} \cot \theta .
\end{gathered}
$$

The path length in this region exceeds $h$ by the amount

$$
\Delta \mathrm{p}=\mathrm{d}+\rho(2 \psi+\theta)-\mathrm{h}=\mathrm{d}(1-\cos \theta)+\rho(2 \psi+\theta-2 \sin \psi-\sin \theta) \text {. }
$$

Some values illustrating the dependences of the transverse and longitudinal dimensions $\mathrm{t}$ And $\mathrm{h}$ on quadrupole magnet size $\mathrm{s}$ are tabulated here, using $\mathrm{e}=2.55 \mathrm{~s}$ :

$\begin{array}{lllllc}\mathrm{s}(\mathrm{m}) & \theta(\mathrm{deg}) & \mathrm{t}(\mathrm{m}) & \psi(\mathrm{deg}) & \mathrm{h}(\mathrm{m}) & \Delta \mathrm{p}(\mathrm{m}) \\ 0.6 & 26.0 & 19.2 & 27.0 & 131.4 & 4.0 \\ 0.7 & 30.8 & 24.2 & 30.5 & 141.3 & 9.6 \\ 0.8 & 35.8 & 29.9 & 34.1 & 158.3 & 13.5 \\ 0.9 & 41.2 & 36.5 & 38.0 & 171.7 & 17.9\end{array}$

For our design we adopt $s=0.7 \mathrm{~m}$, so that $\mathrm{t}=24.2 \mathrm{~m}, \mathrm{~h}=141.3 \mathrm{~m}$, and $\Delta \mathrm{p}=9.6 \mathrm{~m}$.

The ten prepulse beams can be less crowded. We use asterisks for their symbols. If they are pushed to the center as closely as possible, leading to touching squares, the analysis above gives $\psi^{*}=18^{\circ}, \phi^{*}=$ $11.140, a^{*} / \mathrm{s}=1.618$, and $\mathrm{r}^{*}=2.039 \mathrm{~s}$. Thus with our selected value of $s=0.7 \mathrm{~m}$, the radius to the beam centers is $\mathrm{r}^{*}=1.43 \mathrm{~m}$ and the prepulse cone half-angle is $16.6^{\circ}$. On the other hand, if these beams are pushed out as far as possible, so as to touch the outer array of main-pulse beams, their value $b^{*}=(s / 2) / \sin \phi^{*}$ will be close to $c=$ (s/2) $\cot 90$, so that $\phi^{*}=9.11^{\circ}, \psi^{*}=\cot ^{-1}(\cot \phi-2)=13.28^{\circ}$, and the centers are at $\mathrm{r}^{*}=(\mathrm{s} / 2)(\cot \phi-1)=2.62 \mathrm{~s}=1.83 \mathrm{~m}$, and the prepulse cone half-angle is $21.5^{\circ}$. For our design we adopt the prepulse cone half-angle value $\theta^{*}=20^{\circ}$.

The radius of curvature in the postulated bending fields needed to bring the prepulses to the final focus scales with momentum, and we 
may assume that the same scaling applies to the paths in the final quadrupole arrays, so that $\mathrm{d}^{*}=0.8674 \times 25 \mathrm{~m}=21.7 \mathrm{~m}$. The factor 0.8674 is the relativistic value of the momentum ratio, which is not exactly the nonrelativistic ratio $(3 / 4)^{1 / 2}=0.8660$. Using $\rho^{*}=70.1 \mathrm{~m}$ and $\mathrm{e}^{*}=1.6 \mathrm{~s}=1.1 \mathrm{~m}$, we find the values $\mathrm{t}^{*}=11.6 \mathrm{~m}, \mathrm{~h}^{*}=102.4 \mathrm{~m}$, and $\Delta \mathrm{p}^{*}=3.2 \mathrm{~m}$.

\section{Main Pulse Two-sided Illumination}

The configuration of minimum path length leading the two mainpulse beam bundles to opposite sides of the target is shown in the following figure, with $\rho$ the smallest practical radius of curvature determined as above, and $h$ the length defined in the preceding figure. The total path length from the linac exit to the target is

$$
\begin{gathered}
\mathrm{P}=(3 \pi / 2) \rho+\mathrm{h}+\mathrm{g}+\Delta \mathrm{p}, \text { but } \mathrm{g}=\mathrm{h}-\rho, \text { so that } \\
\mathrm{P}=[(3 \pi / 2)-1] \rho+2 \mathrm{~h}+\Delta \mathrm{p} .
\end{gathered}
$$

For the parameters chosen here, $\mathrm{P}=300.3+282.6+9.6=592.5 \mathrm{~m}$. This distance is several times too. long for pure free drift incorporating longitudinal compression of beams having properties required by Meier's parameters. The reason is that the bunch compression factor and the drift distance are interconnected by a parameter which depends on bunch properties, as we will explain in a later section below.

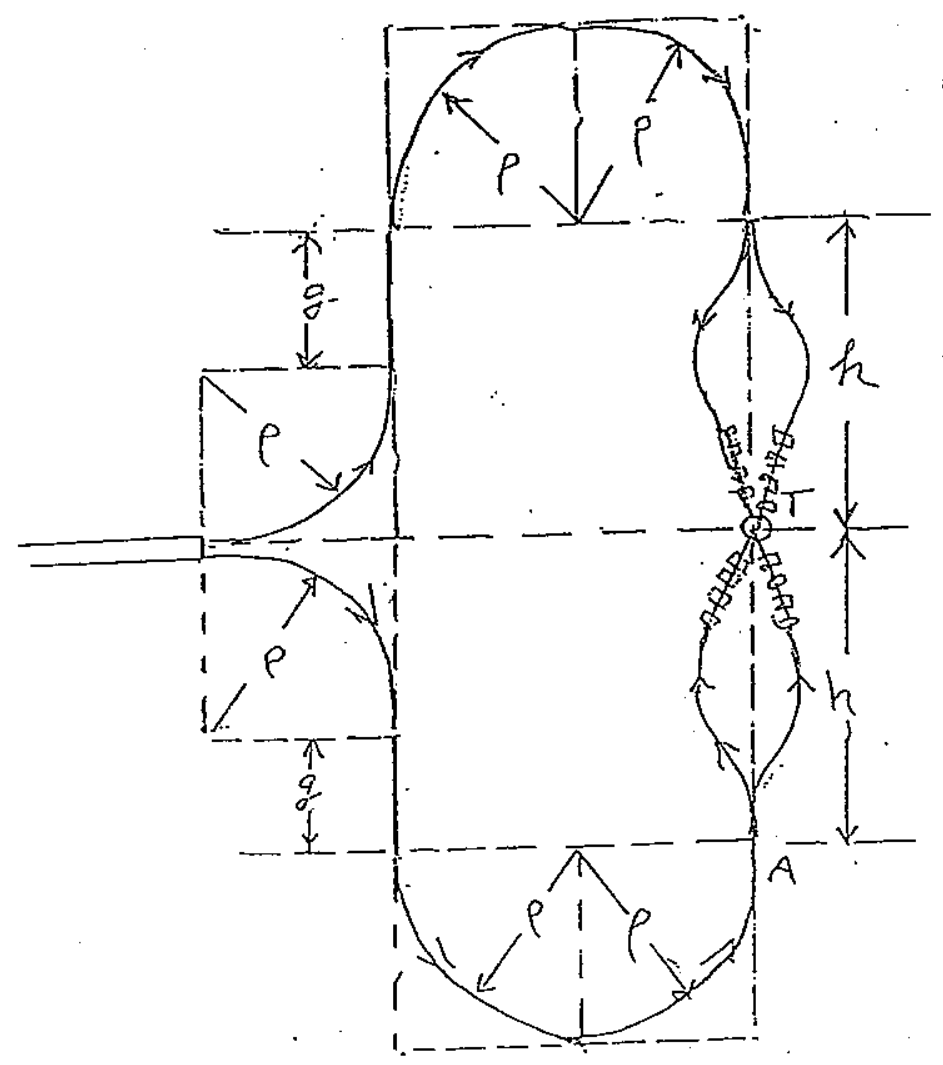




\section{Prepulse Path Parameters}

The prepulse beams are extracted from the linac upstream from its exit by a distance taken by Meier to be $500 \mathrm{~m}$, corresponding to an average accelerating gradient in the linac of $(4-3) \mathrm{GV} /(500 \mathrm{~m})=2$ $\mathrm{MV} / \mathrm{m}$. Nonrelativistically, a pulse requires a time $\mathrm{t}=2 \mathrm{D} /(\mathrm{v} 1+\mathrm{v} 2)$ to traverse a distance $\mathrm{D}$ with constant acceleration, where $\mathrm{v} 1$ and $\mathrm{v} 2$ are the starting and ending velocities. [The relativistic relation is $t=$ $(D / c)\left[(\beta \gamma) 2-(\beta \gamma)_{1}\right] /\left(\gamma_{2}-\gamma_{1}\right)$, with $\beta=v / c$ and $c=$ light speed; however, for small velocities this relation differs from the nonrelativistic one by a factor $\left[1+O\left(\beta_{2}-\beta_{1}\right)^{3}\right]$, with the correction term of order $10^{-5}$ for these main-pulse beams.] This time for a main-pulse beam is $8.75 \mathrm{microsec}$. The prepulse time to pass alongside the linac is $(500 \mathrm{~m}) / \mathrm{v} 1=9.41$ microsec. In going from the linac exit to the target along the path of $592.5 \mathrm{~m}$ indicated above, a main pulse takes additional time $(592.5 \mathrm{~m}) / \mathrm{v} 2=9.68$ microsec, for a total time of 18.43 microsec from where the prepulses leave the linac. (The velocities at $3 \mathrm{GeV}$ and $4 \mathrm{GeV}$ are $\mathrm{v}_{1}=5.316 \times 10^{7} \mathrm{~m} / \mathrm{s}$ and $\mathrm{v}_{2}=6.114 \times 10^{7} \mathrm{~m} / \mathrm{s}$.)

The prepulses are required to arrive at the target about 30 nanosec earlier than the main pulses, but this time corresponds to a path difference of order $2 \mathrm{~m}$, very small compared with paths of order $600 \mathrm{~m}$. Therefore we neglect this small time difference at this stage; it is to be considered in the future for fine tuning. The prepulse external time of flight is then to be $18.43 \mathrm{microsec}$, corresponding to a path length of $979.7 \mathrm{~m}$ at $\mathrm{v} 1$.

The difference $h-h^{*}=141.3-102.4=38.9 \mathrm{~m}$ is advantageous in that the positions at which the tight main-pulse and prepulse beam bundles start to be separated is about 130 feet, which will be welcome in implementing the magnet systems to bring about the separation. Similarly, the difference $t-t^{*}=24.2-11.6=12.6 \mathrm{~m}$ shows that only one of the two expanded bundles will have a large maximum radius to a beam center, the other fitting inside it with a radius smaller by over 40 feet.

If the prepulse beams were to proceed parallel to the linac for the full $500 \mathrm{~m}$ after emerging, and enough further along the same line to 
commence a path scaled from that of the main-pulse beams, their total path length from where they leave the linac would be

$$
\mathrm{p}^{*}=500+3\left(\rho-\rho^{\star}\right)+(3 \pi / 2) \rho^{\star}+\mathrm{h}^{*}+\mathrm{g}^{*}+\Delta \mathrm{p}^{\star}
$$

with $g^{*}=h^{*}-p^{*}$, giving

$$
P^{\star}=500+32.4+260.2+204.8+3.2=1000.6 \mathrm{~m} \text {, }
$$

which exceeds the required length of $979.7 \mathrm{~m}$ by $20.9 \mathrm{~m}$. Therefore this bundle of beams must "cut across the corner" to give a path shorter by that amount. A simple way to accomplish this is shown in the following sketch.

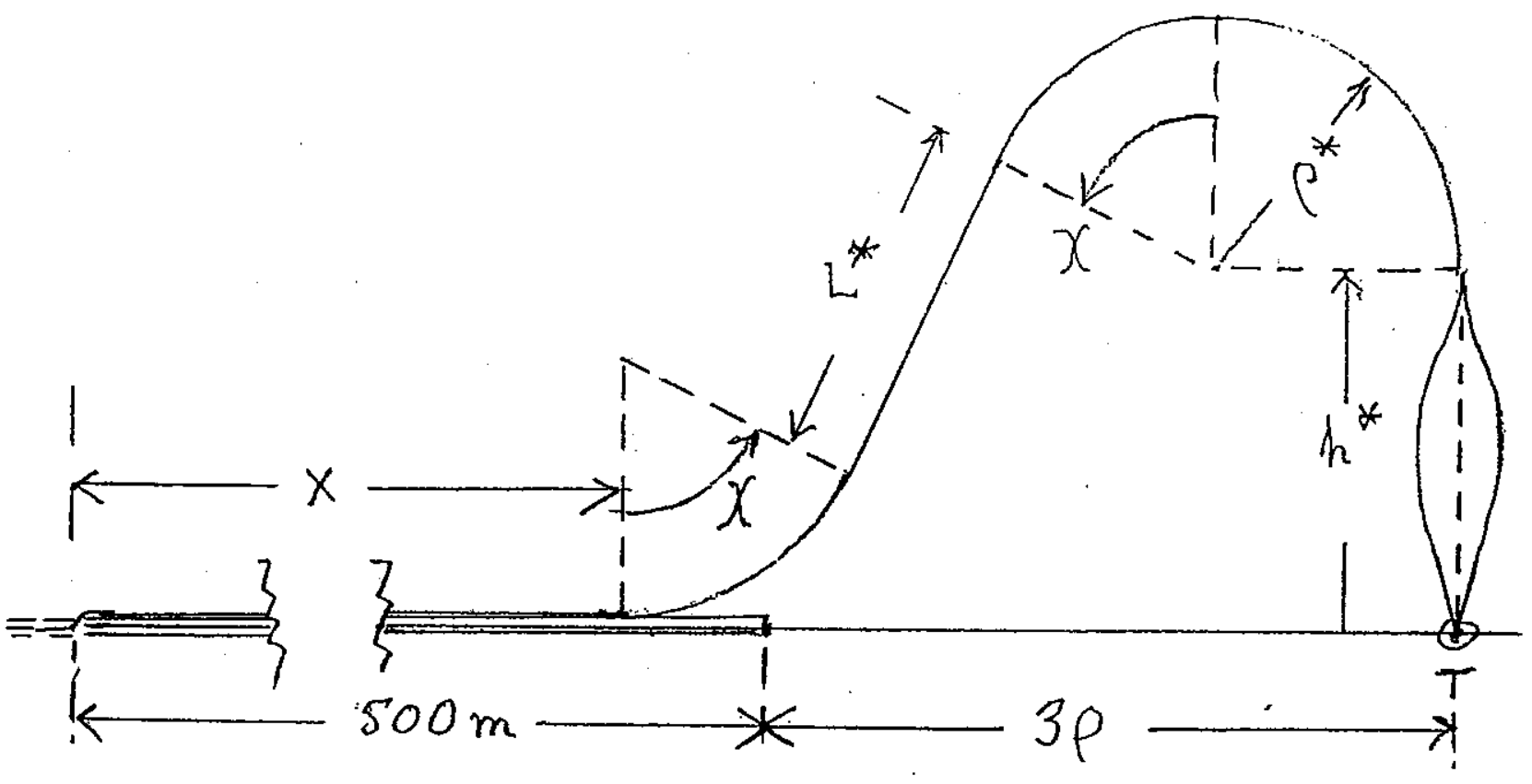

For this geometry

$$
\begin{gathered}
\mathrm{L} \sin \chi+2 \mathrm{p}^{*}(1-\cos \chi)=\mathrm{h}^{*}+\mathrm{p}^{*} \\
\mathrm{~L} \cos \chi+2 \rho^{*} \sin \chi=500+3 \rho-\rho^{*}-\mathrm{x} \\
\mathrm{P}^{*}=\mathrm{x}+\mathrm{L}+[2 \chi+(\pi / 2)] \rho^{*}+\mathrm{h} *+\Delta \mathrm{p}^{*}
\end{gathered}
$$


The numerical values are $\rho^{*}=70.1 \mathrm{~m}, \rho=80.9 \mathrm{~m}, \mathrm{~h}^{*}=102.4 \mathrm{~m}$, $\Delta \mathrm{p}^{*}=3.2 \mathrm{~m}$, and $\mathrm{P}^{*}=979.7 \mathrm{~m}$. The solution of these equations is:

$$
\chi=66.0^{\circ}, \mathrm{L}=98.0 \mathrm{~m}, \mathrm{x}=504.6 \mathrm{~m},
$$

showing that the prepulse beams travel just past the linac exit before beginning their first deflection.

V. Connection Between Compression and Distance in Free Drift

For idealized free drift compression of a bunch with parabolic charge variation, having negligible longitudinal emittance, one assumes that its longitudinal self-field is proportional to the gradient of charge/length and thus is linear in distance along the bunch so that the distribution remains parabolic. The envelope equation for variation of bunch length $\mathrm{L}(\mathrm{t})$. with time under these assumptions is

$$
\mathrm{d}^{2} \mathrm{~L} / \mathrm{dt}^{2}=(12 \mathrm{~g} \mathrm{qe} \mathrm{O}) /\left(4 \pi \varepsilon_{0} \gamma^{5} \mathrm{M}_{\mathrm{OL}}{ }^{2}\right)
$$

in which $\mathrm{g}$ is a geometric factor (taken by Meier to be 1.234), $\mathrm{Q}$ is the total charge in the bunch, qe and $\mathrm{M}_{\mathrm{O}}$ are ion charge and rest mass, and $\gamma$ is the relativistic factor $\mathrm{M} / \mathrm{M}_{\mathrm{O}}$.

It is convenient to introduce dimensionless units. Let $\mathrm{L}(\mathrm{t}) / \mathrm{L}_{\mathrm{O}}=\mathrm{r}^{*}$, the ratio of length to its initial value, and let $t / T^{*}=\mathfrak{u}$, with the time unit $\mathrm{T}^{\star}$ given by

$$
\mathrm{T}^{* 2}=\left(4 \pi \varepsilon_{0} \gamma^{5} \mathrm{M}_{\mathrm{O}} \mathrm{L}_{\mathrm{O}}^{3}\right) /(24 \mathrm{~g} \text { qe } \mathrm{Q}) .
$$

[It is important to note that $\mathrm{T}^{*}$ is not the same as the time unit $\mathrm{T}$ to be introduced later in analyzing regions with external compressive fields.] Then the envelope equation becomes

$$
d^{2} r^{*} / d^{2}=1 /\left(2 r^{* 2}\right) .
$$

The first integral of this equation is

$$
\left(d r^{*} / d u\right)^{2}=\left[\left(d r^{*} / d u\right)_{O}\right]^{2}+1-\left(1 / r^{*}\right),
$$


with the subscript o denoting an initial value. Evaluating at the end of compression, $\mathrm{dr} * / \mathrm{du}=0$ and $1 / \mathrm{r}^{*}=\mathrm{C}$, the maximum compression attained. Thus we have the simple result

$$
\begin{gathered}
C=\left[\left(d r^{*} / d u\right)_{O}\right]^{2}+1 \\
\text { or } C=\left(v_{O} T^{*} / L_{O}\right)^{2}\left(\Delta v_{O} / v_{O}\right)^{2}+1
\end{gathered}
$$

Returning to the first integral for arbitrary $r^{*}$, it can be integrated again by separation of variables:

$$
\begin{gathered}
\mathrm{du}=\mathrm{dr}^{*} /\left[\mathrm{C}-\left(1 / \mathrm{r}^{*}\right)\right]^{1 / 2}, \\
\mathrm{uF}=\mathrm{C}^{-3 / 2}\left\{\left[(\mathrm{C}(\mathrm{C}-1)]^{1 / 2}+\tanh ^{-1}[(\mathrm{C}-1) / \mathrm{C}]^{1 / 2}\right\}\right.
\end{gathered}
$$

Here $\mathrm{uF}_{\mathrm{F}}$ is the dimensionless time at full compression. The drift distance $\mathrm{D}$ to maximum compression is given by

$$
\mathrm{D}=\mathrm{v}_{\mathrm{O}} \mathrm{T}^{*} \mathrm{uF} \text {. }
$$

The function $\mathrm{uF}(\mathrm{C})$ is tabulated and graphed below.

$\begin{array}{llllll}C & \text { uF } & 2(C-1)^{1 / 2} & \text { C } & \text { uF } & C^{-1 / 2} \\ 1.0001 & 0.02000 & 0.02000 & 6 & 0.4778 & \\ 1.001 & 0.0632 & 0.0632 & 8 & 0.4059 & \\ 1.01 & 0.1974 & 0.0200 & 10 & 0.3575 & \\ 1.1 & 0.5572 & 0.6325 & 12 & 0.3224 & \\ 1.5 & 0.8298 & & 14 & 0.2956 & 0.2673 \\ 1.635 & 0.8366 & & 16 & 0.2743 & 0.2500 \\ 1.8 & 0.8301 & & 18 & 0.2569 & 0.2357 \\ 2 & 0.8116 & & 20 & 0.2423 & 0.2236 \\ 3 & 0.6920 & & 25 & 0.2143 & 0.2000 \\ 4 & 0.5976 & & 30 & 0.1940 & 0.1826\end{array}$

The function $\mathrm{uF}$ attains a maximum value of 0.8366 at $\mathrm{C}=1.635$. For $C>>1$, it approaches $C^{-1 / 2}$, while for $C-1$ very small it approaches $2(\mathrm{C}-1)^{1 / 2}$. Both of these limiting regimes will be of interest to us. 


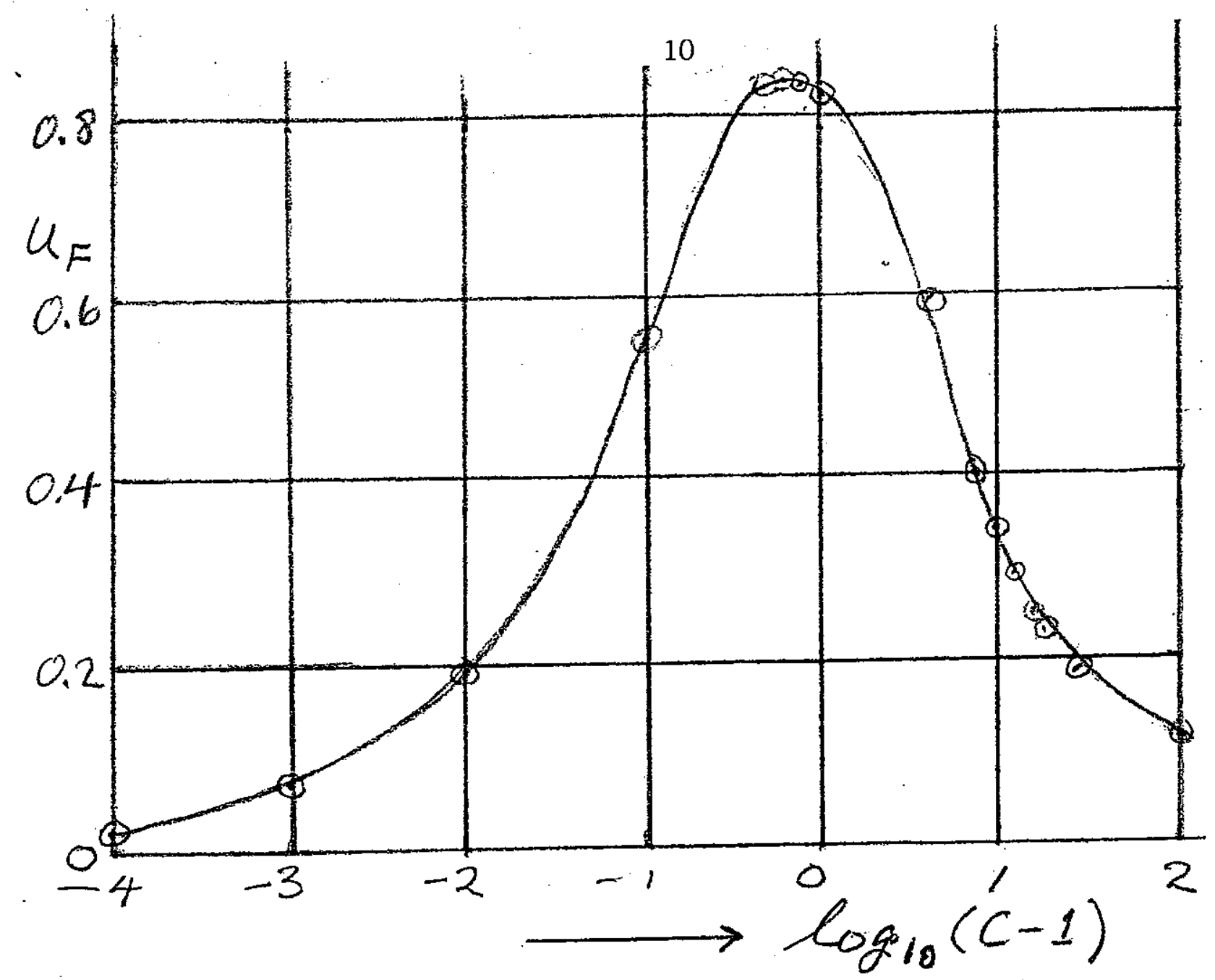

Large Compressions:

$\mathrm{D} \rightarrow \mathrm{v}_{\mathrm{O}} \mathrm{T}^{*} / \mathrm{C}^{1 / 2}, \mathrm{C} \rightarrow\left(\mathrm{VOT}^{*} / \mathrm{L}_{\mathrm{O}}\right)\left(\Delta \mathrm{v}_{\mathrm{O}} / \mathrm{v}_{\mathrm{O}}\right)$ and

$$
\mathrm{D} \rightarrow \mathrm{L}_{\mathrm{O}} /\left(\Delta \mathrm{v}_{\mathrm{O}} / \mathrm{v}_{\mathrm{O}}\right)
$$

Using the expressions above, $\mathrm{D}$ can be written as

$$
\mathrm{D}=\left[\mathrm{L}_{\mathrm{O}} /\left(\Delta \mathrm{v}_{\mathrm{O}} / \mathrm{v}_{\mathrm{O}}\right)\right]\left(1+\mathrm{f}_{\mathrm{C}}\right)
$$

in which the correction term is

$$
f_{C}=C^{-1}\left\{[(C-1) / C]^{1 / 2} \tanh ^{-1}[(C-1) / C]^{1 / 2}-1\right\}
$$

For all compressions larger than about a factor 3 this correction term is less than a few percent, so the drift is moderately well approximated by

$D=\frac{L_{0}}{\Delta V / V}$

$$
\mathrm{D} \approx \mathrm{L}_{\mathrm{O}} /\left(\Delta \mathrm{v}_{\mathrm{O}} / \mathrm{v}_{\mathrm{O}}\right)
$$

$\Rightarrow \frac{D}{V} \triangleq \frac{L_{0}}{A v}$

Time. Time to cosprem

the bain. of 
corresponding to a linear change in L with distance approximately down to zero at the actual position of maximum compression.

\section{Very Small Compressions}

For C-1 very small, $\mathrm{D} \rightarrow 2 \mathrm{v}_{\mathrm{O}} \mathrm{T}^{*}(\mathrm{C}-1)^{1 / 2},(\mathrm{C}-1)^{1 / 2}=\left(\mathrm{v}_{\mathrm{O}} \mathrm{T}^{*} / \mathrm{L}_{\mathrm{O}}\right)\left(\Delta \mathrm{v}_{\mathrm{O}} / \mathrm{v}_{\mathrm{O}}\right)$;

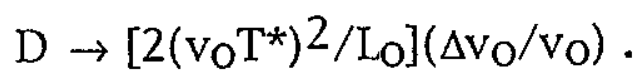

For any particular bunch $\mathrm{T}^{* 2}$ is proportional to $\mathrm{L}_{\mathrm{O}}{ }^{3}$, so $\mathrm{D}$ is proportional to $\left(\mathrm{v}_{\mathrm{O}} \mathrm{L}_{\mathrm{O}}\right)^{2}\left(\Delta \mathrm{v}_{\mathrm{O}} / \mathrm{v}_{\mathrm{O}}\right)$. This result can be understood as a limiting case of constant "length" deceleration;

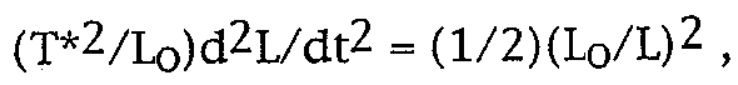

and if $\mathrm{L}$ is replaced by $\mathrm{L}_{\mathrm{O}}$ on the right side, $\mathrm{d}^{2} \mathrm{~L} / \mathrm{ds} \mathrm{s}^{2} \approx(1 / 2) \mathrm{L}_{\mathrm{O}}\left(\mathrm{v}_{\mathrm{O}} \mathrm{T}^{*}\right)^{2}$;

$$
\mathrm{dL} / \mathrm{ds} \approx-\left(\left(\Delta \mathrm{v}_{\mathrm{O}} / \mathrm{v}_{\mathrm{O}}\right)+(1 / 2) \mathrm{L}_{\mathrm{O}} \mathrm{s} /\left(\mathrm{v}_{\mathrm{O}} \mathrm{T}^{*}\right)^{2}\right.
$$

a linear decrease of $\mathrm{dL} / \mathrm{ds}$ with distance, as opposed to a constant inward $\mathrm{dL} / \mathrm{ds}$ for the large-C case. The distance to $\mathrm{dL} / \mathrm{ds}=0$ is

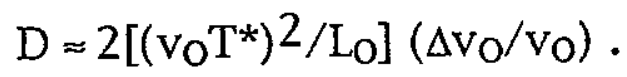

We will make use of the large-C results in the regions just upstream of the target for both main pulse and prepulse bunches; the small-C results will be useful in the regions downstream from the points of exit from the linac.

We now return to demonstrating that distances such as the $600 \mathrm{~m}$ developed for main-pulse bunches from the linac to the target is much too long to be reached by free drift incorporating longitudinal compression. because the velocity tilt appears in both the approximate relation $\mathrm{D} \approx \mathrm{L}_{\mathrm{O}} /(\Delta \mathrm{vo} / \mathrm{vo})$ and in $(\mathrm{C}-1)^{1 / 2}=\left(\mathrm{v}_{\mathrm{O}} \mathrm{T}^{*} / \mathrm{L}_{\mathrm{O}}\right)\left(\Delta \mathrm{v}_{\mathrm{O}} / \mathrm{v}_{\mathrm{O}}\right)$, it can be eliminated. We are interested here in compressions large enough that we may roughly approximnate $\mathrm{C}-1$ by $\mathrm{C}$, giving the important approximate result

$$
\mathrm{CD}^{2} \approx\left(4 \pi \varepsilon_{\mathrm{O}} \gamma^{5} \mathrm{Mov}_{\mathrm{O}}{ }^{2} \mathrm{~L}_{\mathrm{O}}{ }^{3}\right) /(24 \mathrm{~g} \text { qe Q }) .
$$


For the main-pulse bunches in Meier's system these parameters are:

$$
\begin{aligned}
& \gamma=1.02144, \gamma^{5}=1.112,4 \pi \varepsilon_{0}=1 /\left(9 \times 10^{9}\right) \\
& \mathrm{M}_{O}=200 \mathrm{mp}=3.321 \times 10^{-25} \mathrm{~kg} \\
& \mathrm{v}_{O}=6.114 \times 10^{7} \mathrm{~m} / \mathrm{sec} \\
& \mathrm{g}=1.234 \\
& \mathrm{qe}=1.6 \times 10^{-19} \text { Coul } \\
& \mathrm{Q}=26.8 \times 10^{-6} \text { Coul. }
\end{aligned}
$$

If we take $\mathrm{L}_{O}$ to be about $10 \mathrm{~m}$ the value of the product $\mathrm{CD}^{2}$ is about $1.2 \times 10^{6} \mathrm{~m}^{2}$. Therefore if a compression factor of order 20 is to be attained the drift distance must be less than about $240 \mathrm{~m}$. Correspondingly, for a drift distance of $600 \mathrm{~m}$ the compression factor cannot exceed about 3.3. To meet the requirements of this system we must introduce ramped velocity-tilt-changing external electric fields along significant portions of the path. Before considering how this should be done we display a sketch (roughly to scale) of both groups of beams on one side, with the main-pulse beams shown in dashed lines.

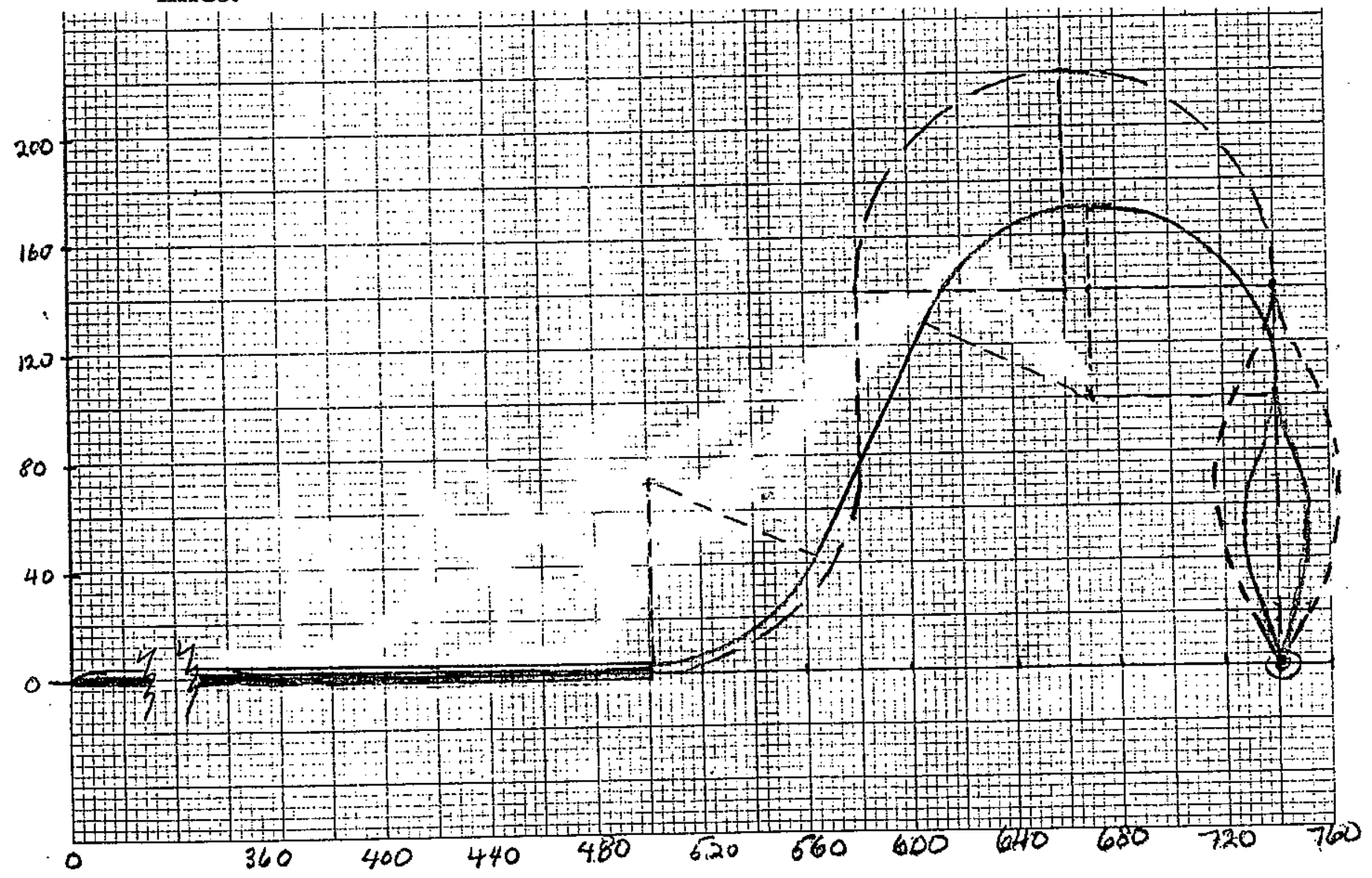


VII. Distances and Pulse Lengths With External Compression Fields

Because a free drift distance greater than about $240 \mathrm{~m}$ is incompatible with a compression factor in that distance of order 20 for beam pulses with Meier's parameters, there must be regions containing external compressing fields. A simple region of this kind contains an external longitudinal field which (when averaged over distance along the transport line) has the form

$$
E_{Z}(e x t)=-\Delta E \text { o }(L)(2 z / L)
$$

with $\mathrm{z}$ the distance from the center of a bunch of (varying) length $\mathrm{L}$. For simplicity we assume here that $\Delta \mathrm{E}_{\mathrm{O}}$ is a constant within a region. In such a region the idealized envelope equation for a parabolic bunch is

$$
\mathrm{d}^{2} \mathrm{~L} / \mathrm{dt}^{2}=-\left(2 \text { qe } \Delta \mathrm{E}_{\mathrm{O}}\right) /\left(\gamma^{3} \mathrm{M}_{\mathrm{O}}\right)+(12 \mathrm{~g} \mathrm{qe} \mathrm{Q}) /\left(4 \pi \vartheta \gamma^{5} \mathrm{M}_{\mathrm{O}}{ }^{2}\right)
$$

the first term on the right producing the compressive acceleration. As before, we introduce dimensionless variables. Let $\mathrm{L}(\mathrm{t}) / \mathrm{L}_{\mathrm{O}}=\mathrm{r}$, as before, and let $\mathrm{t} / \mathrm{T}=\mathrm{w}$, with the new time unit $\mathrm{T}$ (not the same as $\mathrm{T}^{*}$ defined before) given by

$$
\mathrm{T}^{2}=\left(\gamma^{3} \mathrm{M}_{\mathrm{O}} \mathrm{L}_{\mathrm{O}}\right) /\left(4 \mathrm{qe} \Delta \mathrm{E}_{\mathrm{O}}\right)
$$

In addition we define a dimensionless parameter

$$
R=(6 g \mathrm{~g}) /\left(4 \pi \boxminus \gamma^{2} \mathrm{~L}_{\mathrm{O}}{ }^{2} \Delta \mathrm{E}_{\mathrm{O}}\right) \text {. }
$$

The envelope equation becomes

$$
d^{2} r / d w^{2}=(1 / 2)\left[\left(R / r^{2}\right)-1\right]
$$

Its first integral is

$$
(d r / d w)^{2}=(d r / d w)^{2} o+(1-r)(r-R) / r .
$$

We abbreviate the frequently occurring dimensionless first derivative by s;

$$
s=d r / d w, \quad s_{O}=(d r / d w)_{O}
$$


If we evaluate the first integral at the time wf of maximum compression, where $s=0$ and $r=\operatorname{rf}(f=$ final) $=1 / C$ (with $C$ the compression factor), we have a relation connecting so and $\mathrm{rf}$ :

$$
(1-\mathrm{rf})(\mathrm{rf}-\mathrm{R}) / \mathrm{rf}=\mathrm{so}^{2}
$$

The equation can be integrated again by separation of variables;

$$
d w=\left\{r /\left[(1-r)(r-R)+s_{o}^{2} r\right]\right\}^{1 / 2} d r .
$$

The denominator inside the square root may be written in factored form;

$$
(1-r)(r-R)+s_{O}^{2} r=-R+A r-r^{2}=(a-r)(r-b),
$$

in which

$$
A=1+R+s_{O}^{2}, a=\left[A+\left(A^{2-4 R}\right)^{1 / 2}\right]=2 R /\left[A-\left(A^{2-4 R}\right)^{1 / 2}\right], \quad b=R / a .
$$

If we set $u=r / a$ and $p=b / a$,

$$
d w=\{a u /[(1-u)(u-p)]\}^{1 / 2} d u,
$$

which gives a standard form of an elliptic integral, made evident by the substitutions

$$
\mathrm{u}=1-(1-\mathrm{p}) \sin ^{2} \emptyset, \quad 1-\mathrm{p}=\mathrm{k}^{2}
$$

Then

$$
\begin{aligned}
w(r) & =2 a^{1 / 2} \int\left(1-k^{2} \sin ^{2} \varnothing\right)^{1 / 2} d \varnothing \\
= & 2 a^{1 / 2}\left[E(\varnothing(r), k)-E\left(\varnothing_{O}, k\right)\right],
\end{aligned}
$$

in which

$$
\begin{aligned}
& \sin \varnothing(\mathrm{r})=[1-(\mathrm{r} / \mathrm{a})]^{1 / 2} / \mathrm{k}, \\
& \sin \varnothing_{O}=[1-(1 / \mathrm{a})]^{1 / 2 / \mathrm{k}} .
\end{aligned}
$$


Finally, the drift distance to the position where $\mathrm{L}(\mathrm{t})=\mathrm{rL}$ is

$$
\mathrm{D}=\mathrm{v}_{\mathrm{O}} \mathrm{T} w(\mathrm{r}) \text {. }
$$

It is convenient to note that

$$
s_{O}=(d r / d w)_{O}=\left(T / L_{O}\right)(d L / d t)_{O}=\left(v_{O} T / L_{O}\right)\left(\Delta v_{O} / v_{O}\right),
$$

and of course the fractional velocity tilt at any stage is given by

$$
\mathrm{s}=\mathrm{dr} / \mathrm{dw}=\left(\mathrm{v}_{\mathrm{O}} \mathrm{T} / \mathrm{L}_{\mathrm{O}}\right)\left(\Delta \mathrm{v} / \mathrm{v}_{\mathrm{O}}\right)
$$

A particularly simple case is presented if the initial velocity tilt is zero. Then

$$
\begin{gathered}
A=1+R, a=1, b=R, p=R, \\
\sin \emptyset_{O}=0, E\left(\varnothing_{O}, k\right)=0, \text { and } \\
\sin \varnothing(r)=[(1-r) / 1-R)]^{1 / 2} .
\end{gathered}
$$

In that special case $\mathrm{rf}=\mathrm{R}$, so that $\varnothing=\varnothing \mathrm{f}=\pi / 2$, and $E(\varnothing f, k)$ is the complete elliptic integral $\mathrm{E}(\mathrm{k})$.

VIII. Achieving the Required Final Compression

We consider first the main-beam compression. We assume there to be no external compression along the final region of length $h=141.3$ $\mathrm{m}$. We label the path intervals and record their lengths:

$$
\begin{aligned}
& A-B=127.1 \mathrm{~m}=(\pi / 2) \rho \quad \text { (quarter-circle) } \\
& B-C=60.4 \mathrm{~m}=\mathrm{h}-\rho \\
& C-D=254.2 \mathrm{~m}=\pi \rho \text { (half-circle) } \\
& D-T=141.3 \mathrm{~m}=\text { (final region) }
\end{aligned}
$$

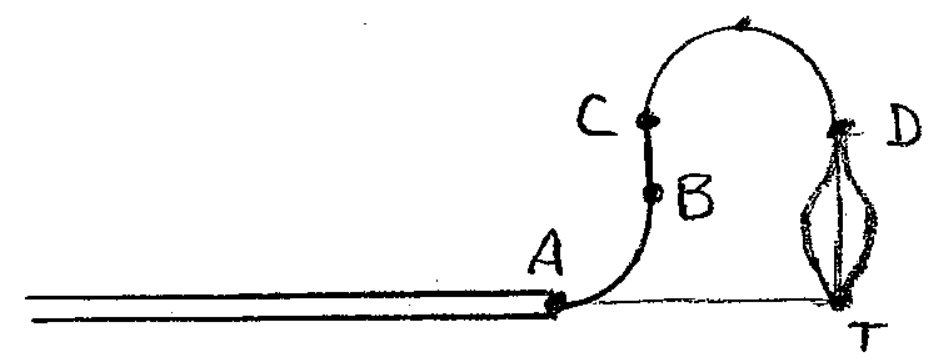


We will work backward from the target $\mathrm{T}$, where Meier's design requires $\mathrm{LT}=0.489 \mathrm{~m}$; the velocity tilt is to be zero there. The formulas given earlier may be used to determine the starting bunch length $\mathrm{LD}$ for which the free drift region $\mathrm{D}-\mathrm{T}$ has the desired length $141.3 \mathrm{~m}$; the result is $\mathrm{LD}=5.164 \mathrm{~m}$, so that $\mathrm{C}=10.56$. The velocity tilt at $\mathrm{D}$ is found to be 0.0378 .

Some idea of the accuracy of the estimate quoted earlier for the large-compression limit can be gained by evaluating it here; the drift distance is approximately the initial bunch length divided by the tilt, giving $136.6 \mathrm{~m}$ rather than the correct value of $141.3 \mathrm{~m}$, an underestimate of over $3 \%$.

The free drift region could be extended upstream from $D$ to a position farther than $141.3 \mathrm{~m}$ from the target; the result would be to increase the bunch length and the tilt further. This change is undesirable because it would require a larger external compressing field further upstream over a greater distance to produce the larger tilt.

In the same way we consider the free-drift prepulse compression on approaching the target. We label the path intervals and record their lengths:

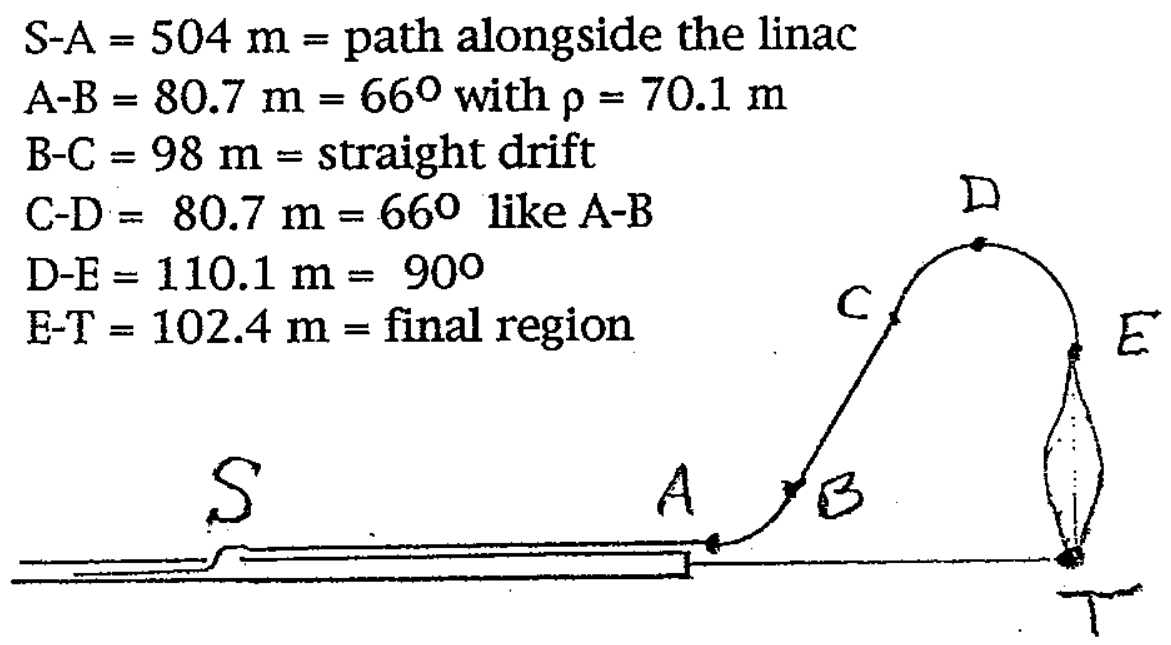

For a prepulse duration on target of 20 nanoseconds and velocity $v_{O}$ $=5.316 \times 10^{7} \mathrm{~m} / \mathrm{s}$, the final bunch length $\mathrm{LT}$ is $1.063 \mathrm{~m}$. Considerations like those for main-pulse bunches provide the values $\mathrm{LE}_{\mathrm{E}}=3.364 \mathrm{~m}, \mathrm{C}=3.135$, and $\Delta \mathrm{vE} / \mathrm{v}_{\mathrm{O}}=0.0267$ corresponding to the length $\mathrm{LE}-\mathrm{T}=102.4 \mathrm{~m}$. Just as for the main pulses, the free-drift region should not be extended further upstream from $E$. 
Next we consider external compression of the main-pulse bunches. Upstream from $D$ the distance $A-B+B-C+C-D=441.7 \mathrm{~m}$ is available in which to apply the external field needed to reduce the bunch length to $5.164 \mathrm{~m}$. (We are assuming that a larger bunch length, of order $10 \mathrm{~m}$, is more appropriate at the linac exit.) Because we have fixed both the bunch length and tilt at $D$, there are three remaining parameters. These are (1) the magnitude $\Delta \mathrm{E}_{\mathrm{O}}$ of the external field (assumed constant in the region); (2) the distance upstream from D to the point (which we will call $\mathrm{Y}$ ) where the external field commences; and (3) the bunch length LY at $Y$; or, equivalently, the ratio $r=$ $\mathrm{LD} / \mathrm{LY}$. If we imagine that the point $\mathrm{Y}$ is where there is no velocity tilt, the calculation from $Y$ to $D$ is facilitated by the simplification pointed out above, with $\mathrm{a}=1, \mathrm{~b}=\mathrm{p}=\mathrm{R}$, and $\sin \emptyset_{\mathrm{O}}=0$. For any assumed value of the bunch length LY (or, equivalently, of $r$ ) at $Y$ there will be a corresponding value of $\Delta \mathrm{E}_{\mathrm{O}}$ that generates the required tilt at $\mathrm{D}$, and in addition defines the distance $\mathrm{Y}-\mathrm{D}$.

The three parameters $r, \Delta \mathrm{E}_{\mathrm{O}}$, and distance dY-D are related by two equations. One of these connects the velocity tilts at $D$ and $Y$ with $r$ and the parameters LD, vo, T, and R. As just stated, the tilt at D and the length $\mathrm{LD}_{\mathrm{D}}$ are regarded as fixed by the considerations above, but this relation is complicated by the dependence of both $\mathrm{T}$ and $\mathrm{R}$ on $\Delta \mathrm{E}_{\mathrm{O}}$ and on $r$ (through $\mathrm{LY}=\mathrm{LD} / \mathrm{r}$ ). We will assume that the tilt vanishes at $Y$, to take advantage of the simplest form of the analysis. Then the equation takes the form

$$
\left(\Delta \mathrm{VD} / \mathrm{V}_{\mathrm{O}}\right)=\left[(\mathrm{LD} / \mathrm{r}) /\left(\mathrm{V}_{\mathrm{O}} \mathrm{T}\right)\right][(1-\mathrm{r})(\mathrm{r}-\mathrm{R}) / \mathrm{r}]^{1 / 2}
$$

Although $T$ depends on fractional powers of $r$ and $\Delta E_{O}$, and $R$ depends on different integral powers, it turns out (rather surprisingly) that a simple equation can be found for $\Delta \mathrm{E}_{\mathrm{O}}$ as a function of $\mathrm{r}$ and the many constants; it is

$$
\Delta \mathrm{E}_{\mathrm{O}}=\left(\mathrm{r} /(1-\mathrm{r})\left[\mathrm{v}_{\mathrm{O}}\left(3 \mathrm{M}_{\mathrm{O}} / 4 \mathrm{qe}\right)\left(\Delta \mathrm{vD} / \mathrm{v}_{\mathrm{o}}\right)\right]^{2} / \mathrm{LD}+\mathrm{r}\left[(6 \mathrm{gQ}) /\left(4 \mathrm{or}^{2}\right)\right] / \mathrm{LD}^{2}\right.
$$

From this relation one finds the function $\Delta \mathrm{E}_{\mathrm{O}}(\mathrm{r})$, and thence the functions $T(r)$ and $R(r)$ needed to evaluate the distance $d Y-D(r)$, so that $r$ labels a one-parameter family of consistent values in the external-compression region. 
The remaining parameter, the distance between $D$ and $Y$, is found from the relation involving the elliptic integrals, only one of which enters into the simplest form of analysis we are using here. The results for the main-pulse parameters are tabulated and graphed below.

\section{MAIN PULSE PARAMETERS}

$\begin{array}{lrrr}\mathrm{r} & \mathrm{LY}(\mathrm{m}) & \Delta \mathrm{E}_{0}(\mathrm{~V} / \mathrm{m}) & \mathrm{DY}-\mathrm{D}(\mathrm{m}) \\ 0.35 & 14.75 & 3.30 \times 10^{5} & 500 \\ 0.45 & 11.48 & 4.97 \times 10^{5} & 320 \\ 0.55 & 9.39 & 7.34 \times 10^{5} & 220 \\ 0.7 & 7.38 & 13.79 \times 10^{5} & 115\end{array}$

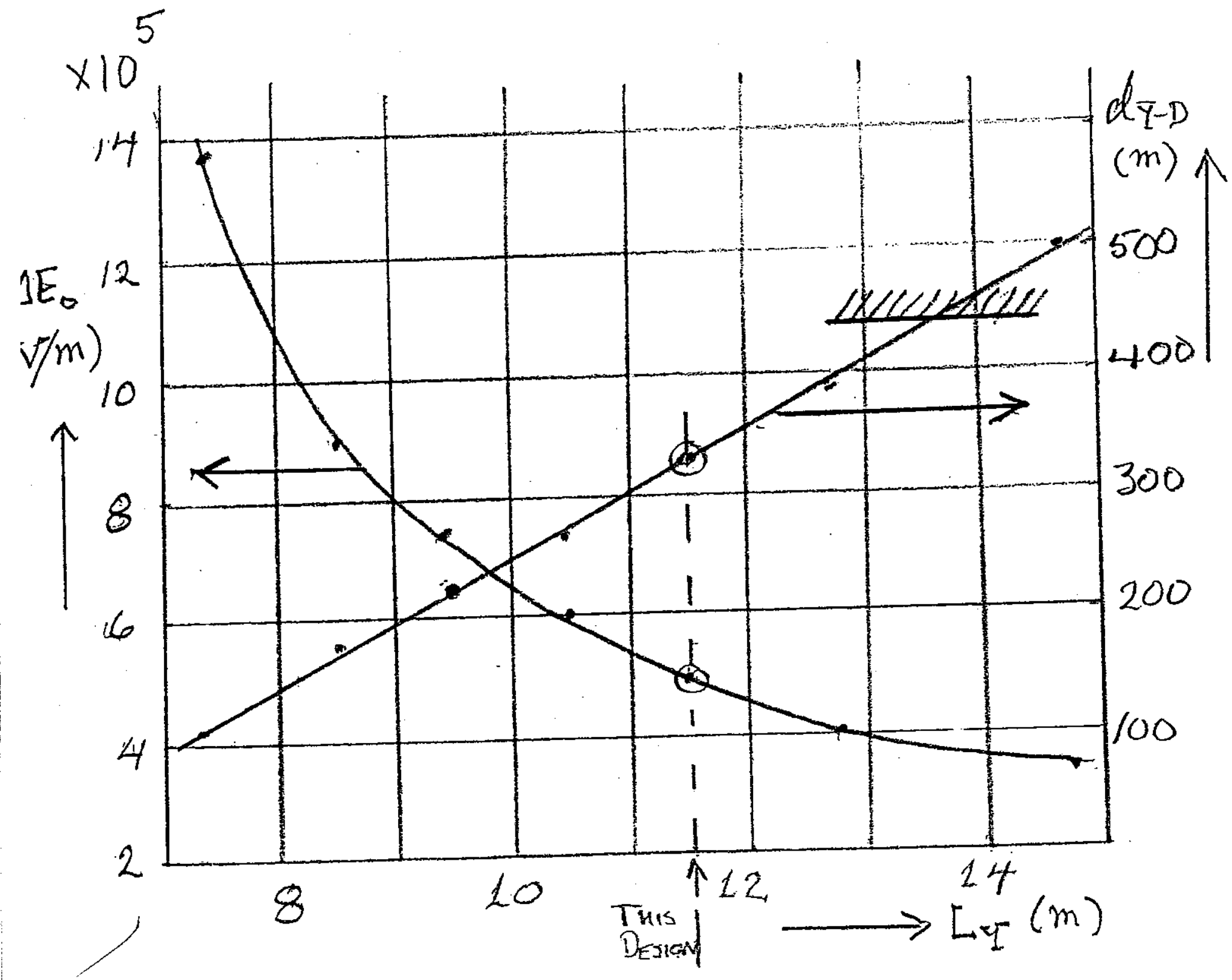


Notice that a compressive field less than about $3.7 \times 10^{5} \mathrm{~V} / \mathrm{m}$ is too small to achieve the corresponding bunch length of about $13.5 \mathrm{~m}$ within the available distance of $440 \mathrm{~m}$.

Assuming that the strategy of the procedure here is appropriate, there is a design decision that will depend on engineering considerations; $150 \mathrm{~m}$ of $10^{6} \mathrm{~V} / \mathrm{m}$ is to be compared with $400 \mathrm{~m}$ of $4 \times 10^{5} \mathrm{~V} / \mathrm{m}$ as to cost and technical difficulty. More generally, it is seen that for these bunches large compressive fields over long distances are required to produce a $3.8 \%$ velocity tilt.

We will proceed by assuming that a lower external field over a longer distance is preferred. To produce a specific design we arbitrarily choose $5 \times 10^{5} \mathrm{~V} / \mathrm{m}$ over a distance of $320 \mathrm{~m}$. This choice means that point $Y$ is essentially at point $B$, the end of the first $90^{\circ}$ bend. The remaining task for the main-pulse bunches is to transport them over a distance $A-B=127.1 \mathrm{~m}$ from the linac exit at $A$ to point $B$, where they are to have length $L B=11.5 \mathrm{~m}$ and zero velocity tilt. The simplest procedure is to require the bunches emerging from the linac to have almost the same length and a very small tilt, which is gradually brought to zero at point $\mathrm{C}$ after a free drift.

To make this quantitative we employ the notation used earlier to explain the connection between compression, tilt, and distance in free drift. Here we will be in the limit where $\mathrm{C}-1$ is very small.

$$
\begin{gathered}
\mathrm{d}^{2} \mathrm{r}^{*} / \mathrm{du}^{2}=1 /\left(2 \mathrm{r}^{* 2}\right), \\
\mathrm{r}^{*}=\mathrm{L}(\mathrm{u}) / \mathrm{LA}_{\mathrm{A}}, \quad \mathrm{u}=\mathrm{t} / \mathrm{T}^{*} .
\end{gathered}
$$

With no tilt at $B$, the initial tilt is given by

$$
\Delta \mathrm{vA} / \mathrm{v}_{\mathrm{O}}=\left(\mathrm{LA} / \mathrm{v}_{\mathrm{O}} \mathrm{T}^{*}\right)(\mathrm{C}-1)^{1 / 2}
$$

and the distance to $B$ is

$$
\mathrm{d}_{\mathrm{A}-\mathrm{B}}=\mathrm{v}_{\mathrm{O}} \mathrm{T}^{*} \mathrm{uF}(\mathrm{C})=127.1 \mathrm{~m}
$$

with $\mathrm{C}=\mathrm{L}_{\mathrm{A}} / \mathrm{LB}_{\mathrm{B}}$. Using expressions for $\mathrm{T}^{*}$ and $\mathrm{uF}$ given earlier, 


$$
\mathrm{d}_{\mathrm{A}-\mathrm{B}}=\mathrm{vo}_{\mathrm{O}}\left[\left(4 \pi \varepsilon_{\mathrm{O}} \gamma^{5} \mathrm{M}_{\mathrm{O}}\right) /(24 \mathrm{~g} \text { qe } \mathrm{Q})\right]^{1 / 2} \mathrm{LB}^{3 / 2}\left[\mathrm{C}^{3 / 2} \mathrm{uF}(\mathrm{C})\right]
$$

numerically,

$$
\begin{gathered}
C^{3 / 2} \mathrm{uF}(\mathrm{C})=\left[127.1 /\left(34.75 \times(115)^{3 / 2}\right]=0.0938\right. \\
=[c(c-1)]^{1 / 2}+\tanh ^{-1}[(c-1) / C]^{1 / 2} .
\end{gathered}
$$

Solving numerically for $C, C=1.0022$, so that $L_{A}$ and $L_{B}$ differ by only $3 \mathrm{~cm}$, and $\mathrm{v}_{\mathrm{O}} \mathrm{T}^{*}=135.5 \mathrm{~m}$. The tilt required at $\mathrm{A}$ is the very small value 0.0040 .

It is realized that this scheme places the burden of emitting bunches with length about $11.5 \mathrm{~m}$ and negligible tilt on the accelerating system within the linac, but its accelerating fields are specified to average $2 \times 10^{6} \mathrm{~V} / \mathrm{m}$ over the last 500 meters, so the waveform shaping required to meet this condition is a small perturbation.

It may seem surprising that a bunch can drift over $100 \mathrm{~m}$ with negligible velocity tilt and change its length so little, but this is the calculated behavior of an idealized bunch in idealized surroundings characterized by the single parameter $\mathrm{g}$, in the limit of small compression described above in detail. To maintain real bunch properties close to those calculated here will require monitoring systems and carefully applied correcting impulses similar in character to those needed in the linac to control momentum spread and bunch length there.

The prepulse bunches will also require external compression. Upstream from $\mathrm{E}$ the distance A-B + B-C + C-D + D-E $=80.7+98.0+$ $80.7+110.1=369.5 \mathrm{~m}$, considerably less than the corresponding distance of $441.7 \mathrm{~m}$ for main-pulse bunches. [However, this distance could be further increased by about $500 \mathrm{~m}$ if the portion of the prepulse path running along outside the linac were to be included.] Using all of it will require the smallest external field, but if this field is unnecessarily low a shorter distance may be less costly. As before, we assume no tilt at the start of this region beginning at a point $Y$. For any assumed value of LY there will be a corresponding value of $\Delta \mathrm{E}_{\mathrm{O}}$ that generates the required tilt at $\mathrm{F}$, and in addition defines the distance Y-F. Some illustrative values and a graph are given here: 
PREPULSE PARAMETERS

$\begin{array}{lrll}r & \text { LY }(\mathrm{m}) & \Delta \mathrm{EO}(\mathrm{V} / \mathrm{m}) & \mathrm{DY}-\mathrm{E}(\mathrm{m}) \\ 0.25 & 13.46 & 1.47 \times 10^{5} & 675 \\ 0.35 & 9.61 & 2.29 \times 10^{5} & 440 \\ 0.45 & 7.48 & 3.36 \times 10^{5} & 290 \\ 0.55 & 6.12 & 4.83 \times 10^{5} & 200 \\ 0.65 & 5.18 & 7.05 \times 10^{5} & 130 \\ & & & \\ 10^{5} & & & \end{array}$

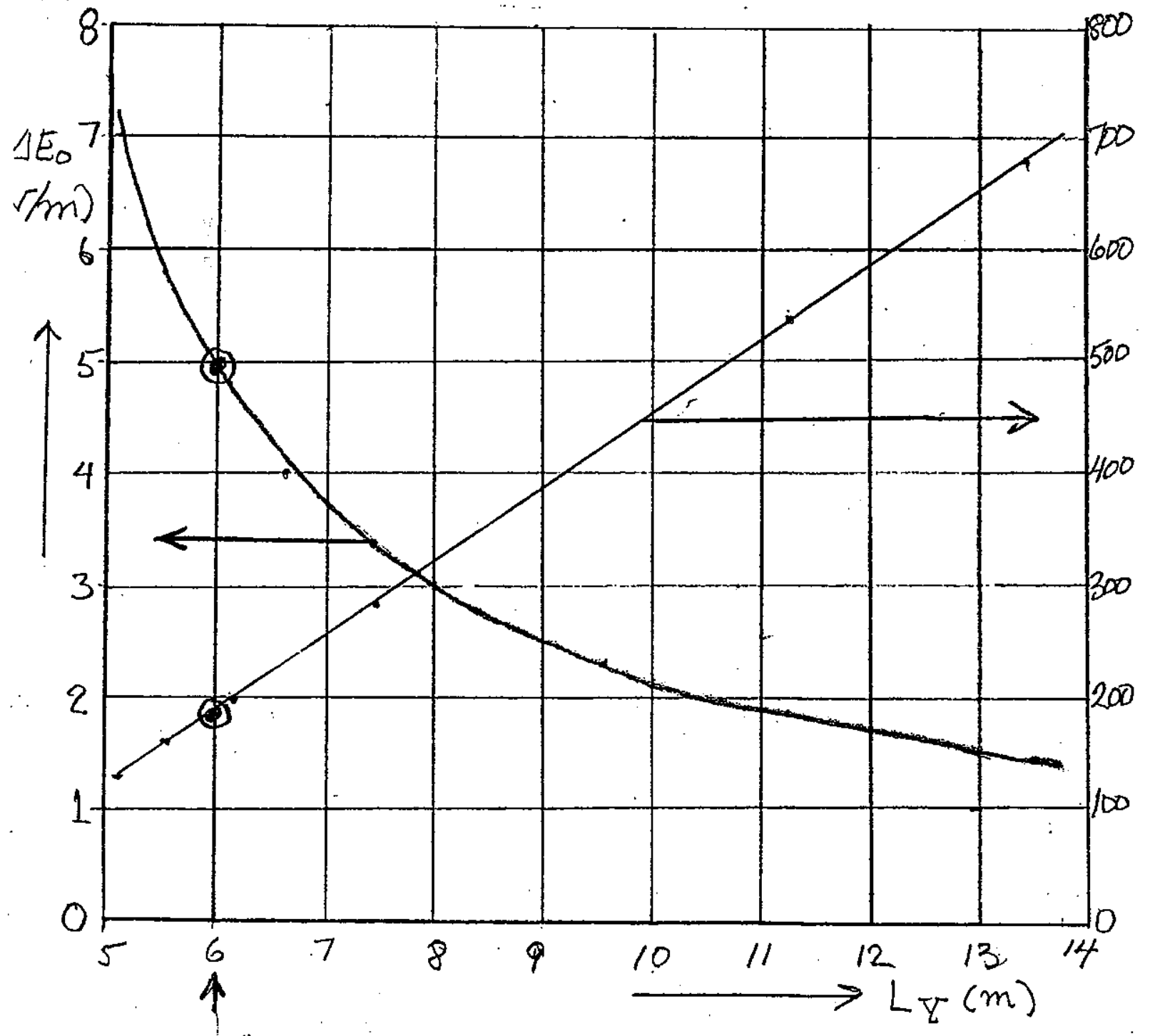

THIS

Design 
Here again we will have need of engineering and cost comsiderations to determine the best choice of distance and compressive field. If we use a distance of about $360 \mathrm{~m}$ a small field of about $2.8 \times 10^{5} \mathrm{~V} / \mathrm{m}$ will be needed, while if the field is $5 \times 10^{5} \mathrm{~V} / \mathrm{m}$, as chosen above for the main-pulse beams, the distance will be about $190 \mathrm{~m}$. We arbitrarily make the latter choice so as to produce a specific design; the point $Y$ then coincides with point $C$, at the downstream end of the slanted straight-drift prepulse path segment B-C. This means that the prepulse bunches must travel from $S$ where they leave the linac a distance $504+81+98=683 \mathrm{~m}$ to arrive at $C$ with no velocity tilt and a bunch length of $6.0 \mathrm{~m}$.

To determine how this is to be accomplished we make a free-drift calculation like that made above for the main-pulse bunches, using the prepulse value of $\gamma$ and replacing $L_{A}$ by $L_{S}, L_{B}$ by $L_{C}$, and 127 $\mathrm{m}$ by $683 \mathrm{~m}$. The results are: compression factor $\mathrm{C}=1.52$; LS $=9.12$ $\mathrm{m} ;$ and $\Delta \mathrm{v}_{\mathrm{O}} / \mathrm{v}_{\mathrm{O}}=0.0080$.

As for the main bunches, this solution is not unique, because a different position for Y couild have been chosen.; however, it seems a reasonable one imposing no difficult requirements. A requirement is placed on the linac to produce bunches at $3 \mathrm{GeV}$ with a specific length, selected here as $9.12 \mathrm{~m}$, and very small velocity tilt, calculated to be $8.0 \times 10^{-3}$.

\section{Tolerances}

It is evident that this system requires very high precision in its construction and operation. A few comments suffice to indicate the needs. The relative pulse arrival times at the target must presumably be accurate with a tolerable error of a few nanoseconds; at a velocity near $6 \times 10^{7} \mathrm{~m} / \mathrm{s}$ this corresponds to a path length error of $10-20 \mathrm{~cm}$ over a path of order $800 \mathrm{~m}$, a precision of order $10^{-4}$. A defect in the length of all main-pulse lines could be accomodated by a corresponding adjustment of the pellet injection time, but differing path-length errors in prepulse and main-pulse lines, or among the many lines in each group, are unacceptable.

The path length difference due to a very small error in a bending field is significant. For the main-pulse lines the total principal bending angle is $3 \pi / 2$ in a radius of $80 \mathrm{~m}$; to hold the path length 
change to about $10 \mathrm{~cm}$ requires a tolerance $\Delta \mathrm{B} / \mathrm{B}$ of about $4 \times 10^{-4}$. This corresponds to a field error of $10^{-3} \mathrm{~T}$ in a field of $4 \mathrm{~T}$, and refers again to differences among the many lines, about 60 in number in Meier's system.

Methods to detect, measure, and correct such errors, and to control the lengths and shapes of non-idealized bunches in their real environment, are not considered in the present discussion, nor are the properties of transverse containment systems.

\section{Thoughts on an Improved Design}

The sensitivity of the scenario developed by Meier (based on a target design due to Tabak and Callahan) to various changes is not known. The dependence of the main-pulse cone angle at the target on the number of main-pulse beams can be deduced from the analysis of the packing of squares in an annulus given early in this report. The numbers 20,10, and 30 of beams are not particularly felicitous with regard to snug packing for transport. For this reason a detailed plan for separating and guiding the two groups of particles is not presented here. Twelve beams, rather than ten, pack better, as a four-by-four square array with corners omitted, and twenty-one beams pack better in a five-by-five array without corners. For convenient separation of the two groups of beams on approach to the target it sould be desirable to have a well-packed array including all beams, in which the prepulse beams are all near the axis and the main=pulse beams are all outside. An array of $5+16=21$ beams has this property. The cost and complexity of the transport lines would be significantly reduced if a smaller number of beams could be used. However, the greatest benefit for beam transport would be realized by development of a design for single-sided illumination of the target. This benefit is detailed in the following section.

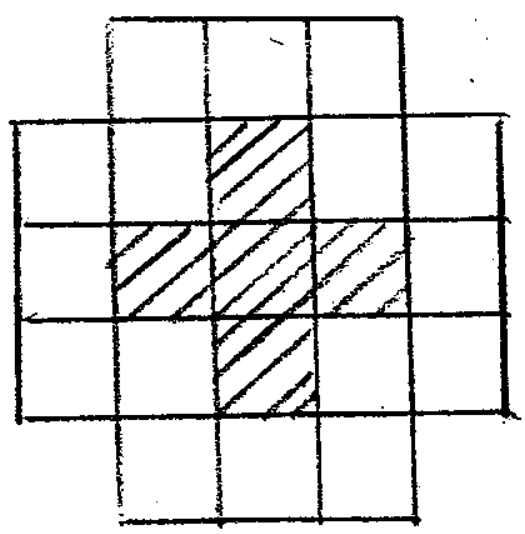


XI. Comparison of the Present Design with One-sided Illumination

PRESENT DESIGN

Total path length of beams:

$\begin{array}{lr}\text { Main pulses: } & 40 \times 593 \mathrm{~m}=23.7 \mathrm{~km} \\ \text { Prepulses: } & 20 \times(480+500) \mathrm{m}=\frac{19.6 \mathrm{~km}}{43.3 \mathrm{~km}} \\ \text { Total: } & \end{array}$

Total path length in $1.6 \mathrm{~T}$ mean bending field:
Main pulses:
$40 \times 511 \mathrm{~m}=20.4 \mathrm{~km}$
Prepulses:
Total:
$20 \times 351 \mathrm{~m}=\frac{7.0 \mathrm{~km}}{27.4 \mathrm{~km}}$

Total path length in $\pm 5 \times 10^{5} \mathrm{~V} / \mathrm{m}$ ramped compressive field:

Main pulses:

Prepulses:

Total:
$40 \times 320 \mathrm{~m}=12.8 \mathrm{~km}$

$20 \times 190 \mathrm{~m}=\frac{3.8 \mathrm{~km}}{16.6 \mathrm{~km}}$

These lengths may be contrasted with those estimated for a hypothetical system using one-sided illumination. In order to make a direct comparison I have assumed that each beam in the one-sided system may have twice the current so that a total of twenty mainpulse and ten prepulse beams suffice. [A different assumption would require recalculating the cones of beam lines approaching the target under arbitrary guidelines; some element of realism may be restored to the comparison by multiplying the one-sided-illumination path lengths by a factor between one and two.]

ONE-SIDED ILLUMINATION

Total path length:

Main pulses:

Prepulses:

Total:

$$
20 \times 151 \mathrm{~m}=3.0 \mathrm{~km}
$$

$10 \times(144+500) \mathrm{m}=\underline{6.4 \mathrm{~km}}$

$9.4 \mathrm{~km}$

Compare 9.4 ( $\mathrm{x}$ 2?) with $43.3 \mathrm{~km}$ in the present design.

Total path length in $1.6 \mathrm{~T}$ mean bending field:

Main pulses:

Prepulses:

$20 \times 130=2.6 \mathrm{~km}$

Total:

$10 \times 80=0.8 \mathrm{~km}$

$3.4 \mathrm{~km}$

Compare 3.4 (x2?) with $27: 4 \mathrm{~km}$ in the present design. 
Total path length in ramped compressive field:

Zero.

In the hypothetical one-sided design the linac must produce main pulses having exit length $5.16 \mathrm{~m}$ and tilt $3.8 \%$, and prepulses having exit length $3.4 \mathrm{~m}$ and tilt $2.7 \%$, if these beams are to correspond with the calculations of free drift to the target in the present design.

\section{Summary}

Main pulse beams (drawn for one side):

$\begin{array}{llllcc}\text { Position } & \mathrm{x}(\mathrm{m}) & \mathrm{y}(\mathrm{m}) & \mathrm{L}(\mathrm{m}) & \text { Path from } \mathrm{A} & \Delta \mathrm{v} / \mathrm{v}_{\mathrm{O}} \\ \mathrm{A} & 0 & 0 & 11.5 & 0 & 0.0040 \\ \mathrm{~B} & 80.9 & 80.9 & 11.5 & 127.1 & 0 \\ \mathrm{C} & 80.9 & 141.3 & & 187.5 & \\ \mathrm{D} & 242.7 & 141.3 & 5.13 & 441.7 & 0.0378 \\ \mathrm{~T} & 242.7 & 0 & 0.489 & 533.0 & 0 \\ & & & & +\frac{+9.6}{592.6} & \end{array}$

In $\mathrm{B}-\mathrm{D}, \Delta \mathrm{E}_{\mathrm{O}}=5 \times 10^{5} \mathrm{~V} / \mathrm{m}$

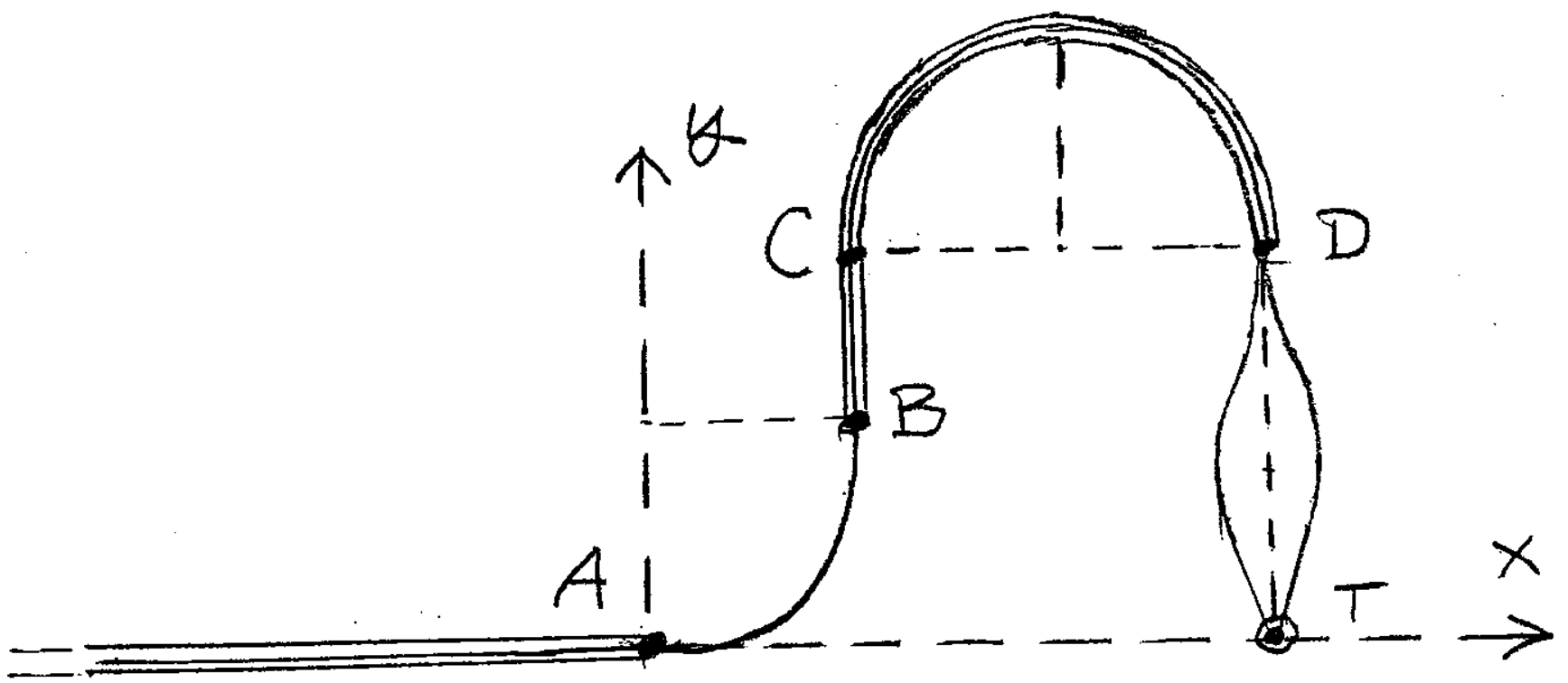


Prepulse Beams (drawn for one side)

Position $x(m) \quad y(m) \quad L(m)$ Path from A Path from $S \quad \Delta v / v_{O}$

$\begin{array}{lcccccc}\mathrm{S} & -500 & 0 & 9.12 & -504.6 & 0 & 0.0080 \\ \mathrm{~A} & 4.6 & 0 & & 0 & 504.6 & \\ \mathrm{~B} & 68.6 & 41.6 & & 80.7 & 585.3 & \\ \mathrm{C} & 108.5 & 131.1 & 6.00 & 178.7 & 683.3 & 0 \\ \mathrm{D} & 172.6 & 172.7 & & 259.4 & 764.0 & \\ \mathrm{E} & 242.7 & 102.6 & 3.36 & 369.5 & 814.1 & 0.0267 \\ \mathrm{~T} & 242.7 & 0 & 1.063 & 476.9 & 976.5 & 0 \\ & & & & +3.2 & +3.2 & \\ & & & & =475.1 & = & \end{array}$

In $\mathrm{C}-\mathrm{E}, \Delta \mathrm{E}_{\mathrm{O}}=5.0 \times 10^{5} \mathrm{~V} / \mathrm{m}$.

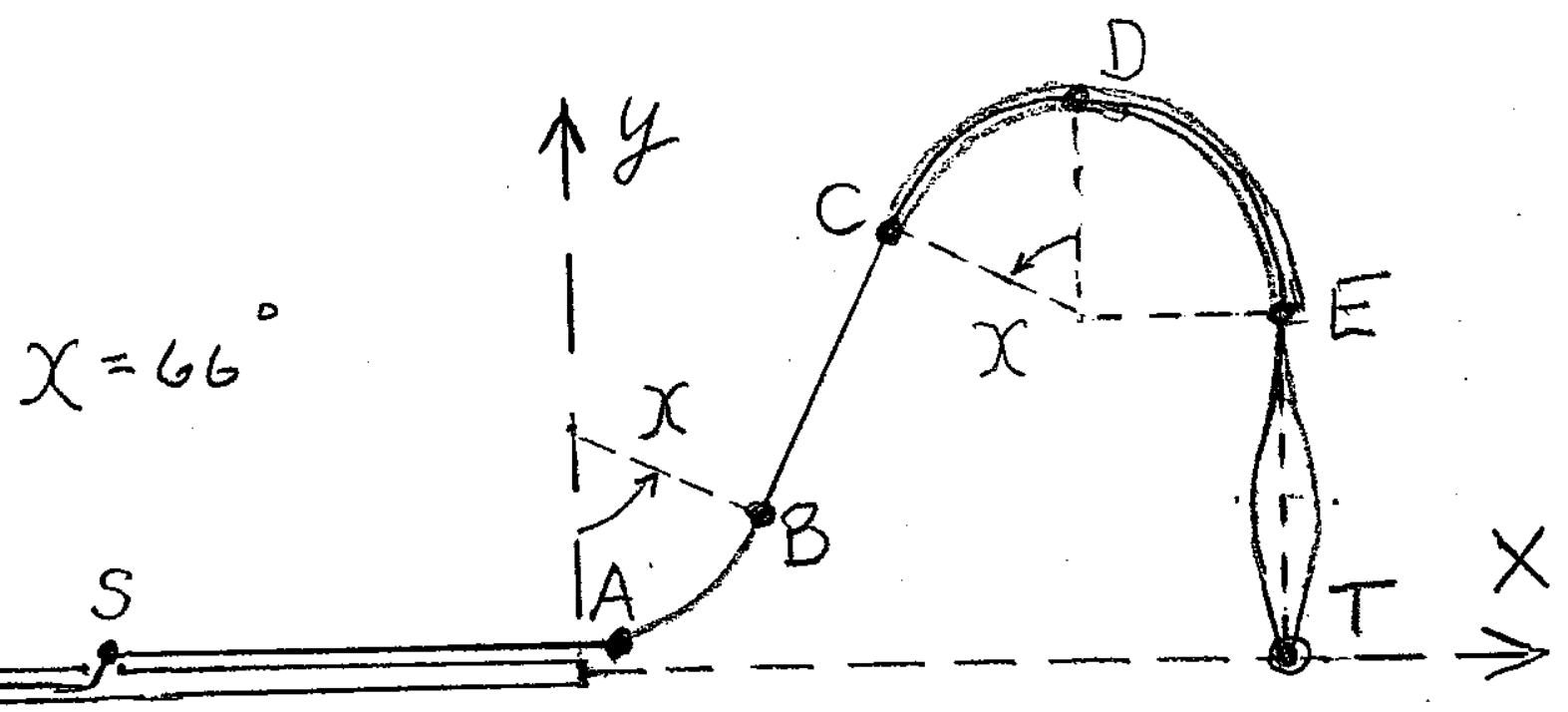

